\title{
A Política Fiscal do Plano Real e o Ajuste Fiscal para 1999/2001
}

\author{
Fiscal policy of Real Plan and the \\ fiscal adjustment for 1999/2001
}

ANA PAULA RAMOS*

RESUMO: O principal objetivo deste artigo é analisar os resultados da gestão da política fiscal no Brasil no período entre 1994 e 1999. A ideia central do texto é que não houve mudança significativa na gestão fiscal durante o período, mesmo considerando as programa de ajuste sob o acordo do FMI. A ênfase da política tem sido a abordagem de curto prazo, baseada no aumento das receitas fiscais como forma de evitar a deterioração dos déficits primários. Por outro lado, as reformas estruturais necessárias para apoiar o ajuste fiscal foram adiadas continuamente.

PALAVRAS-CHAVE: Plano Real; ajuste fiscal; estabilização; inflação; estrutura do gasto público.

ABSTRACT: The main purpose of this article is to analyze the results of fiscal policy management in Brazil during the period between 1994 and 1999. The central idea of the text is that there was no significant change in the fiscal management during the period, even considering the fiscal adjustment program under the IMF arrangement. The policy's emphasis has been the short run approach, based on the raising of the fiscal revenues as a way to avoid primary deficits deterioration. In contrast, the structural reforms necessary to support the fiscal adjustment have been continuously postponed.

KEYWORDS: Real Plan; fiscal adjustment; stabilization; inflation; public expenditure structure.

JEL Classification: E31; E62.

\section{INTRODUÇÃO}

O objetivo principal deste texto é avaliar a política fiscal adotada pelo governo federal desde a introdução do Plano Real no que se refere à sua capacidade de

\footnotetext{
* Mestre em Economia pela Universidade Estadual de Campinas - UNICAMP e pesquisadora do Instituto de Pesquisa Econômica Aplicada - IPEA, Rio de Janeiro/RJ, Brasil. E-mail: apramos@ipea.gov.
} 
concretizar o ajuste das contas públicas em bases sustentáveis a longo prazo. O trabalho procura confrontar o relativo sucesso da gestão fiscal estritamente de curto prazo - especialmente no que diz respeito à razoável capacidade do Executivo de manter o resultado primário sob controle através da ampliação das fontes de recursos do setor público - com a lentidão dos resultados obtidos com as reformas estruturais.

O trabalho foi dividido em quatro seções, inclusive esta introdução. Na segunda fazemos a descrição e análise das principais medidas de política fiscal adotadas durante a vigência do Plano Real, enfatizando seus aspectos de curto e longo prazos. A terceira seção está dedicada à análise do conteúdo do programa de ajuste fiscal proposto dentro do acordo financeiro celebrado com o FMI no final de 1998. Nossa principal argumentação é que as bases que sustentam esse novo programa de ajuste não divergem substancialmente da tónica empregada em toda a condução da política fiscal no período 1994-98, qual seja, a adoção de medidas emergenciais de contenção do déficit público a fim de garantir um certo controle das contas públicas no curto prazo enquanto se aguarda a concretização das reformas fiscais de cunho estrutural. Uma conclusão encerra o trabalho.

\section{A POLÍTICA FISCAL E AS REFORMAS DO PERÍODO 1994-1998}

Desde a introdução do Plano Real, parecia estar evidente para os formuladores da política económica a importância do ajustamento das contas públicas, em particular das contas primárias, no processo de consolidação da estabilidade econômica. Uma demonstração disso reside no fato de que, a despeito da formulação da estratégia anti-inflacionária do plano ter se baseado numa combinação de instrumentos de política cambial e comercial, à época já havia a percepção de que com a queda da inflação alguns dos desequilíbrios entre fluxos de receitas e despesas primárias seriam explicitados, podendo dificultar as primeiras fases do programa. ${ }^{1}$ Havia também a percepção de que o elevado volume de despesas rígidas no âmbito do governo federal (gastos com pessoal, previdência social e despesas vinculadas) tinha conduzido a um certo engessamento do Orçamento federal, gerando fortes pressões sobre as contas fiscais.

Nesse sentido, a solução dos principais desequilíbrios fiscais no âmbito das contas primárias demandava alterações profundas tanto na estrutura de receitas quanto de despesas do setor público consolidado, as quais exigiriam um processo lento de reformas de uma série de dispositivos constitucionais e legais.

Diante desse quadro, a opção da política fiscal foi pela via de menor resistência, ou seja, a adoção de medidas temporárias de ajuste que objetivavam ampliar a capacidade de gestão das contas públicas enquanto as reformas estruturais, que

\footnotetext{
${ }^{1}$ Para uma avaliação mais detalhada do mix de política econômica que balizou o Plano Real e seus efeitos ver Ramos (1998). Ver também Banco Central do Brasil (1996).
} 
deveriam garantir bases sólidas para o ajustamento de longo prazo do setor público, seriam encaminhadas para votação no Congresso. De acordo com essa linha de argumentação, a política fiscal adotada ao longo da gestão do Plano Real pode ser separada em duas frentes de ação: (i) a primeira, nitidamente composta de medidas de curto alcance, cujo objetivo era apenas contornar os desajustes mais prementes enfrenta dos pelo governo; e (ii) um conjunto de medidas voltadas para o ajuste estrutural do setor público, as quais seriam adotadas paralelamente a essa ação de curto prazo.

\section{A Política fiscal de Curto Prazo do Plano Real}

As medidas fiscais adotadas conjuntamente com o programa de estabilização introduzido em julho de 1994 concentraram-se primordialmente na esfera do governo federal, baseando-se nos seguintes pontos: (i) criação do Fundo Social de Emergência (FS[), mecanismo temporário de desvinculação de receitas orçamentárias, posteriormente substituído pelo Fundo de Estabilização Fiscal (FEF) em 1996; e (ii) promoção de um conjunto de alterações no setor tributário, as quais visavam ampliar a arrecadação federal.

A criação do FSI/FEF permitiu ao governo federal liberar, ao longo do seu período de vigência ${ }^{2}$, a utilização de $20 \%$ dos recursos orçamentários que antes permaneciam vinculados a despesas específicas, inclusive repasses a estados e municípios. A lógica da criação do fundo era reduzir o nível de rigidez das despesas do governo federal, o qual havia se ampliado progressivamente ao longo das últimas duas décadas e poderia inviabilizar a gestão das contas públicas no curto prazo, devido ao fim da alta inflação.

Assim, mesmo sendo uma medida precária devido ao seu caráter temporário e de alcance restrito - dado que produz efeitos sobre uma parcela relativamente pequena dos gastos federais - é inegável que a criação do fundo contribuiu com a melhora das condições de gestão dos recursos fiscais. Deste modo, mesmo com o fim do regime de alta inflação, que funcionava como um mecanismo de mascaramento das inconsistências das contas públicas, a flexibilização de parte do Orçamento foi importante para reduzir as pressões existentes sobre o Orçamento Federal, contribuindo no sentido de evitar que possíveis excessos de despesa gerassem pressões por financiamento inflacionário.

Conjuntamente à criação do FSE, foram tomadas medidas de cunho administrativo visando reforçar a arrecadação federal através do combate à evasão fiscal. Promoveram-se também alterações na estrutura tributária por meio da elevação de algumas alíquotas ${ }^{3}$ e da criação do IPMF (Imposto Provisório sobre Movimentação

\footnotetext{
${ }^{2}$ De acordo com a lei que criou o FEF em 1996 em substituição ao FSE, o fundo deverá vigorar até dezembro de 1999. A prorrogação do mesmo por um ou mais exercícios fiscais dependerá de nova aprovação no Congresso Nacional

${ }^{3}$ Em 1994 houve uma reestruturação, por faixas, das alíquotas do Imposto de Renda Retido na Fonte
} 
Financeira). Os efeitos imediatos dessas medidas refletiram-se na ampliação de $12,6 \%$, em termos reais, das receitas administradas pela Secretaria da Receita Federal (SRF) entre 1994 e 1995. Em 1996, o crescimento real da arrecadação administrada foi bem mais modesto que no ano anterior $(+3,6 \%)$ devido ao fim da cobrança do IPMF. Nos anos seguintes, a estrutura de alíquotas dos impostos e tributos federais voltou a sofrer uma série de modificações - dentre elas a reedição do imposto sobre movimentações financeiras, em 1997, como contribuição provisória (a CPMF) - sempre com o objetivo de tentar adequar, no curto prazo, a arrecadação às necessidades crescentes de recursos. Como resultado, nos anos de 1997 e 1998 as receitas administradas cresceram em torno de 8\% a.a. (ver Tabela 1).

Contudo, a despeito do sucesso obtido no campo da arrecadação federal, o fato mais preocupante diz respeito ao caráter precário da ampliação dessas receitas ao longo do período 1994-98. Tal crescimento deveu-se, em grande medida, à adoção de instrumentos transitórios tais como: (i) a introdução de novos impostos e/ou contribuições provisórias (caso típico do IPMF/CPMF); (ii) elevações temporárias de alíquotas; (iii) obtenção de receitas extraordinárias ${ }^{4}$ originadas na concessão de serviços públicos à iniciativa privada, etc. Como se pode ver pela Tabela 1 , a participação do item demais receitas - o qual inclui a arrecadação extraordinária do Tesouro Nacional - no total da arrecadação federal (exclusive receitas do INSS) ampliou-se continuamente ao longo do período acima, especialmente entre 1997 e 1998, quando essa participação se ampliou de $5 \%$ para $11,5 \%$. Tal salto explica-se pelo elevado volume de receitas extraordinárias auferidas pelo Tesouro em 1998, R \$ 13,5 bilhões, dos quais $\mathrm{R}$ \$ 9,2 bilhões corresponderam à concessão de serviços de telecomunicações. A participação do IPMF/CPMF na arrecadação total também foi bastante significativa desde sua introdução em 1994, respondendo, em média, por $7 \%$ do total das receitas administradas pela SRF.

Porém, a análise da Tabela 2 demonstra que, mesmo diante do relativo sucesso das medidas acima descritas, os resultados primários do governo federal sofreram uma contínua deterioração entre 1994 e 1996, apresentando ligeira recuperação no período 1997-1998, sem, contudo, retornar ao patamar de 1994. Tal comportamento deveu-se ao fato de as despesas totais terem apresentado um crescimento real muito mais forte que o verificado na arrecadação.

sobre os rendimentos do trabalho, passando a faixa de $25 \%$ para $26,6 \%$ e criando-se uma nova faixa de $35 \%$. A alíquota da Contribuição Social sobre o Lucro Líquido do setor financeiro também foi elevada de $23 \%$ para 30\%, a partir de julho de 1994 .

${ }^{4}$ Consideramos como receitas extraordinárias ou atípicas aquelas originadas: i) da concessão de serviços de utilidade pública à iniciativa privada; ii) da alteração de regras no sistema de tributação que geram efeitos em apenas um período, como por exemplo a tributação de estoque de aplicações financeiras ocorrida em 1998; iii) incorporações de lucros e/ou dividendos de empresas estatais nas receitas do Tesouro, entre outras. No caso das receitas de concessão o caráter extraordinário se deve ao fato de que parte dos recursos obtidos com o programa de privatização de algumas estatais foi considerada como receita de concessão, sendo, portanto, utilizada para financiar gastos correntes do governo. Teoricamente, esses recursos deveriam ter sido classificados como receita de privatização e utilizados para abatimento da dívida pública. 
Tabela 1

Participação da CPMF e das Receitas Não-Tributárias na

Arrecadação Federal (R\$ milhões de dez./1998)

\begin{tabular}{|c|c|c|c|c|c|}
\hline & 1994 & 1995 & 1996 & 1997 & 1998 \\
\hline Total Geral da Arrecadação & 88.236 & 100.402 & 103.952 & 114.609 & 133.144 \\
\hline \multicolumn{6}{|l|}{ Receitas Administradas pela } \\
\hline Secretaria da Receita Federal (SRF) & 85.898 & 96.738 & 100.269 & 108.888 & 117.782 \\
\hline Demais Receitas* & 2.338 & 3.664 & 3.682 & 5.720 & 15.362 \\
\hline IPMF/CPMF & 6.826 & 194 & - & 7.199 & 8.168 \\
\hline Demais Receitas/Receitas Totais & $2,65 \%$ & $3,65 \%$ & $3,54 \%$ & $4,99 \%$ & $11,54 \%$ \\
\hline IPMF-CPMF/Receitas Administradas & $7,95 \%$ & $0,20 \%$ & - & $6,61 \%$ & $6,93 \%$ \\
\hline
\end{tabular}

Fonte: Secretaria da Receita Federal.

* Receitas não provenientes de tributos ou contribuições, inclusive receitas de concessão.

A análise desagregada dos gastos mostra que, além do excessivo peso representado pelos gastos com pessoal e encargos da União (ativos e inativos) - 70\% do total das despesas -, esses dois itens tomados em conjunto apresentaram taxa de crescimento entre 1994 e 1998 claramente superior à de outro item importante das despesas, os gastos com custeias e investimentos, que se elevaram $43 \%$, enquanto as primeiras cresceram $52 \%$.

Nem mesmo a política restritiva quanto à contratação e concessão de reajustes salariais ${ }^{5}$ aos servidores públicos imposta pelo governo federal foi capaz de conter significativamente os gastos com pessoal. Merece destaque o comportamento das despesas com inativos, que ampliaram fortemente sua participação no total das despesas com pessoal do serviço público federal nos últimos anos. Entre 1993 e 1994 essa participação passou de 37,9\% para $41 \%$ - ou algo próximo de R 19 bilhões ao ano, a preços de dezembro de 1997 - oscilando em torno desse patamar desde então. Contudo, as receitas obtidas com a contribuição dos servidores públicos para a seguridade social não superam $15 \%$ do valor acima, gerando um déficit que deve ser coberto às custas de recursos do Tesouro Nacional. ${ }^{6}$

Quanto às despesas com benefícios previdenciários do INSS, estas seguiram uma trajetória de ascensão ainda mais acentuada que as despesas com pessoal e encargos durante o período em análise. Passaram de 32,4\% da despesa primária

\footnotetext{
${ }^{5}$ Mesmo deixando de conceder reajustes salariais generalizados para o funcionalismo público, o governo federal implementou ao longo do período do Plano Real uma política de reestruturação de algumas carreiras do serviço público, fato que levou à concessão de reajustes salariais diferenciados para as mesmas. Esse fato, aliado ao cumprimento de algumas sentenças judiciais, explica basicamente o crescimento da folha de servidores ativos da União.

${ }^{6}$ A importância assumida pelos desequilíbrios do sistema de previdência na determinação dos resultados fiscais nos últimos anos levou alguns autores a considerar que o déficit primário do setor público se “transformou num déficit previdenciário" (ver Velloso, 1998).
} 
em 1994 para 35,3\% e em 1998. Muito embora o déficit de caixa do INSS seja significativamente menor do que o déficit das contas previdenciárias dos servidores públicos federais, a relação benefícios/receitas tem se expandido rapidamente e, desde 1996, superou a unidade. Em consequência desse fato, em 1997 os gastos com benefícios do INSS superaram a arrecadação em R \$ 3,6 bilhões. Em 1998, o déficit saltou para $\mathrm{R} \$ 7,2$ bilhões, devido basicamente à ampliação real de 7,8\% das despesas acompanhada de uma estagnação das receitas.

A observação das contas dos Tesouro demonstra que houve também ampliação, em termos reais, na rubrica que engloba os gastos com custeias e investimentos (OCC) que, teoricamente, seria o item sobre o qual o governo possuiria maior poder discricionário e onde poderia realizar cortes de maneira mais ágil, reduzindo parte dos desequilíbrios ficais. Contudo, tais cortes acabaram não se efetivando e a rubrica de OCC passou a incorporar despesas vinculadas a partir de 1997 (repasses ao Ministério da Saúde) por conta da criação da CPMF, gerando também uma certa rigidez nesse item de gastos (ver também Além e Giambiagi, 1999, item 4).

Tabela 2

Resultados Primário e Operacional do Governo Federal ( $R$ \$ milhões de dez/1998)

\begin{tabular}{lrrrrr}
\hline & $1994^{* *}$ & $1995^{* *}$ & $1996^{* *}$ & $1997^{* *}$ & $1998^{* *}$ \\
\hline Receita Total & 127.680 & 149.897 & 153.456 & 165.828 & 185.092 \\
Receita do Tesouro & 95.018 & 109.269 & 103.428 & 113.864 & 138.601 \\
$\quad$ Receita do INSS & 32.662 & 40.628 & 45.677 & 46.204 & 46.491 \\
Receita Líquida* & 110.607 & 126.914 & 129.334 & 139.662 & 157.700 \\
Despesa Total & 95.441 & 120.583 & 129.124 & 136.402 & 152.069 \\
$\quad$ Pessoal e Encargos & 34.583 & 44.425 & 46.116 & 44.760 & 46.174 \\
$\quad$ Benefícios Previdenciários & 30.921 & 40.501 & 46.427 & 49.820 & 53.686 \\
Outros Custeios e Investimentos & 30.807 & 34.927 & 30.732 & 35.871 & 44.205 \\
Outras*** & $(870)$ & 729 & 5.850 & 5.952 & 8.004 \\
Resultado Primário & 15.166 & 6.331 & 210 & 3.260 & 5.631 \\
Despesas com Juros Reais & 10.323 & 17.016 & 17.554 & 13.523 & 54.136 \\
Resultado Operacional & 4.843 & $(10.685)$ & $(17.345)$ & 10.263 & $(48.505)$ \\
\hline
\end{tabular}

* Receita Total exclusive Transferências a Estados e Municípios.

** Dados atualizados pelo IGP-DI.

*** Inclui ajuste do FAT. Operações Oficiais de Crédito, Seguro Desemprego, Desap. Reforma Agrária e Fundos Regionais.

Resultado positivo $=$ superávit e resultado negativo $=$ déficit.

Fonte: Boletim de Acompanhamento Macroeconômico da Secretaria de Política Econômica, diversos números,

Boletim Banco Central. 
Assim, diante do exposto acima, pode-se afirmar que a gestão fiscal levada à frente no período 1994-1998, apesar de bem-sucedida no que tange à ampliação das fontes de receita para o governo federal, não foi capaz de impedir a acentuada expansão dos gastos, resultando numa forte redução do superávit primário nos três primeiros anos do programa de estabilização, à qual se seguiu apenas uma tímida recuperação entre 1997 e 1998. Adicionalmente, observou-se expressiva ampliação do déficit operacional por todo o período, cujas implicações para a trajetória da dívida pública serão discutidas na terceira seção. Nesse sentido, parece claro que ao longo do período acima a solução efetiva dos principais problemas que têm gerado crescentes desajustes fiscais foi postergada à medida que se aguardava o encaminhamento das chamadas "reformas estruturais".

\section{As Reformas Estruturais e suas Implicações para o Ajuste Fiscal}

No âmbito das chamadas reformas estruturais, os avanços alcançados no período 1994-98 podem ser sintetizados em quatro pontos básicos:

(i) aprovação das reformas constitucionais da ordem econômica, que propiciaram um novo perfil para atuação do Estado brasileiro no campo econômico e criaram as condições legais para a ampliação do Programa Nacional de Desestatização (PND), iniciado no final dos anos 80;

(ii) elaboração de uma agenda de reestruturação das contas dos estados, incluindo metas de ajuste financeiro, patrimonial e administrativo, com o principal objetivo de buscar a solvência intertemporal dessas esferas de governo;

(iii) aprovação da reforma administrativa, cujo principal objetivo é fornecer os instrumentos necessários à redução das despesas com pessoal, principalmente através da alteração nas regras de estabilidade do servidor público; e

(iv) aprovação da reforma previdenciária, considerada fundamental para controlar um dos principais focos de geração de déficit primário no âmbito do governo federal e das esferas sub-nacionais de governo.

$\mathrm{O}$ aspecto estrutural do PND não se encontra limitado tão-somente à redução da presença direta do Estado na esfera econômica, mas prende-se, igualmente, ao processo de ajustamento patrimonial das contas fiscais que seria obtido com a utilização dos recursos originados na privatização para o abatimento do estoque de dívida pública. Em termos absolutos, o PND alcançou resultados expressivos, tendo arrecadado cerca de US\$ 88,3 bilhões entre 1991 e 1999 (julho), segundo o BNDES, com a venda de estatais nas três esferas de governo. A despeito do comprometimento do governo federal com a utilização desses recursos para abatimento do estoque de dívida pública - o mesmo não pode ser generalizado quando se avalia o comprometimento de estados e municípios com o processo -, tal fato não impediu o rápido crescimento do estoque da dívida devido às implicações da gestão 
das políticas monetária e cambial no período 1994-98, conforme veremos na seção seguinte.

No que se refere ao ajuste das contas de estados e municípios, o principal resultado obtido no período 1994-1998 diz respeito ao processo de reestruturação das dívidas dos governos estaduais. Esse processo envolveu a assunção por parte do governo federal de um montante superior a R\$ 86 bilhões em dívidas (dívidas mobiliária e contratual dos estados junto aos bancos estaduais), assim como o seu refinanciamento por um prazo de 30 anos a um custo bastante favorável aos devedores $^{7}$. Em contrapartida, os estados ficaram proibidos de emitir novos títulos durante o período de vigência dos contratos de renegociação das dívidas. Adicionalmente, foi criado um programa de reorganização dos bancos estaduais - o PROES - visando o saneamento dos mesmos com vistas à posterior privatização.

Outro aspecto positivo no âmbito das finanças públicas estaduais relaciona-se à criação de vários instrumentos de restrição ao endividamento dessas esferas de governo. Um exemplo disso foi a aprovação da Resolução 78/98 do Senado Federal, que veda a contratação de operação de crédito de qualquer natureza por estados que tenham apresentado resultado primário negativo nos últimos doze meses anteriores à solicitação do empréstimo. Essa resolução introduz também a exigência de cumprimento de um cronograma gradual de redução da relação dívida total/ receita líquida real.

No entanto, essas medidas ainda não foram suficientes para ajustar as contas de estados e municípios, as quais permaneceram em crescente desequilíbrio nos últimos anos (ver Tabela 3). Adicionalmente à questão do endividamento, um importante foco de desajuste das finanças estaduais diz respeito aos gastos com pessoal. O expressivo comprometimento dos orçamentos com pagamentos de servidores públicos ativos e inativos tem sido um importante obstáculo à redução do déficit primário dos governos estaduais, levando muitas vezes à atrofia das demais atividades desempenhadas por esses governos, tais como gastos na área de saúde e educação, devido à escassez crônica de recursos. E a solução definitiva desse problema está intimamente ligada aos resultados que serão obtidos com a aprovação e regulamentação das Reformas Administrativa e da Previdência, tratadas a seguir.

A recente aprovação da Reforma Administrativa, apesar de ser um importante passo em direção à criação de mecanismos que permitam o ajuste efetivo das contas públicas nas três esferas de governo, ainda não pôde gerar efeitos sobre as contas públicas, pois grande parte das alterações aprovadas não são auto-aplicáveis,

\footnotetext{
${ }^{7}$ Além do sensível alongamento dos prazos das dívidas estaduais, o processo de renegociação envolveu a troca de títulos de emissão estadual que pagavam juros de mercado por títulos federais. O custo de endividamento junto ao governo federal girou em torno de $6 \%$ a $7,5 \%$ a.a. acima da variação do IGP, conforme as garantias oferecidas por cada estado. A título de comparação, a taxa Selic média nos anos de 1997 e 1998, período em que a maior parte dos acordos se concretizou, foi de $24 \%$ e $28,5 \%$ a.a. respectivamente, e o IGP foi de 7,9\% e 3,9\% a.a. nos mesmos anos.
} 
exigindo sua regulamentação através de lei complementar. Os principais pontos aprovados até meados de 1999 foram (Ministério da Administração e Reforma do Estado, 1999): (i) revisão das regras de estabilidade do servidor público; (ii) redução do número de cargos de confiança em pelo menos $20 \%$; (iii) demissão de servidores não estáveis; (iv) proibição de recriação de cargos extintos; e (v) alteração das regras de colocação dos servidores em disponibilidade.

A revisão das regras de estabilidade estabelece duas novas possibilidades de demissão dos servidores públicos: por insuficiência de desempenho - apurada em avaliação periódica - e por excesso de quadros - caracterizado pela elevação das despesas com pessoal ativo e inativo relativamente às receitas acima de determinado percentual ( $50 \%$ no caso da União e $60 \%$ no caso dos estados e municípios). Contudo, tanto a definição dos critérios de desempenho mínimo a serem exigidos dos servidores, quanto o percentual máximo de comprometimento das receitas fiscais com pagamento de folha de salário exigem regulamentação através de Lei Complementar, e apenas o segundo critério já foi objeto de aprovação pelo Congresso Nacional. A reforma prevê também que seja estabelecido um prazo (até o final do primeiro semestre do ano 2000) para a adequação por parte da União, estados e municípios às regras acima. Durante este período, o cumprimento do limite de comprometimento das receitas será garantido através de redução dos cargos em comissão, demissão de funcionários não estáveis e, apenas após esgotadas estas possibilidades, pela demissão de funcionários estáveis, ficando extinto o cargo ocupado pelo mesmo por um período de quatro anos. A alteração nas regras de colocação de servidores públicos em disponibilidade também garante que estes não mais recebam seus salários integralmente, passando a remuneração a ser proporcional ao tempo de serviço.

Diante do exposto acima, fica claro que a imposição de todas essas restrições à demissão de servidores públicos significa limitações efetivas ao alcance da Reforma Administrativa, ao menos no curto prazo. Ademais, no caso da União, o com prometimento com folha salarial encontra-se abaixo de $50 \%$ da receita líquida, dando indicação de que não haverá cortes significativos de servidores federais. Os efeitos esperados da Reforma Administrativa no âmbito federal, como anunciados pelo próprio governo, estão muito mais relacionados à melhora na qualidade dos serviços prestados que à redução significativa dos quadros de servidores federais.

No caso dos estados, porém, a adequação aos limites de comprometimento de receita poderá ter efeito positivo uma vez que, conforme dados da Secretaria do Tesouro Nacional, em 1998 a franca maioria dos estados possuía relação despesas com pessoal/receita líquida superior a $60 \%$. Dentre os estados com maiores problemas com pagamento de pessoal encontram-se Minas Gerais, Rio de Janeiro e Rio Grande do Sul, além do Distrito Federal, onde o comprometimento da receita com pessoal ultrapassa $78 \%$ da receita total líquida.

Cabe destacar ainda que, dada a importância crescente das despesas com inativos no conjunto de gastos com pessoal do setor público, a redução dessas últimas 
irá exigir, além das medidas passíveis de adoção em decorrência da aprovação da Reforma Administrativa, uma solução definitiva dos desajustes do sistema previdenciário. Em outras palavras, deverá envolver um conjunto de alterações no modelo previdenciário brasileiro bastante mais amplas que aquelas contidas no texto da Reforma da Previdência, o qual analisaremos a seguir.

A reforma da Previdência, aprovada no Congresso Nacional em fins de 1998, introduz um conjunto de alterações nas regras da aposentadoria dos funcionários públicos e trabalhadores da iniciativa privada que podem ser sintetizadas como segue:

(i) substituição da regra de contagem do tempo para a aposentadoria com base no tempo de serviço pelo tempo de contribuição; (ii) ampliação do tempo mínimo de contribuição em cinco anos, relativamente às regras anteriores; (iii) combinação de tempo de contribuição e limite de idade, apenas no caso dos servidores públicos; e (iv) fim da aposentadoria proporcional.

O Quadro 1 apresenta uma comparação entre as regras vigentes até a aprovação da reforma e as novas regras, as quais serão válidas para os trabalhadores que ingressaram no mercado de trabalho após 16/12/1998.

Para os trabalhadores que já haviam ingressado no mercado de trabalho anteriormente à data acima, sejam servidores públicos ou segurados do INSS, deverá ser observado um conjunto adicional de requisitos para a obtenção da aposentadoria, as chamadas "regras de transição", sintetizadas no Quadro 2. O principal objetivo das regras de transição é ampliar o prazo de contribuição dos atuais participantes do sistema a fim de atenuar as pressões de curto prazo sobre o mesmo, haja vista que os efeitos da reforma sobre os novos participantes do sistema deverão ocorrer apenas a longo prazo.

Uma análise detida dos principais pontos alterados pela reforma demonstra que sua capacidade de reduzir significativamente os desequilíbrios estruturais enfrentados pelo sistema global de previdência são bastante limitados. Um dos pontos que suscitou grande polêmica quando da votação do texto da reforma no Legislativo foi a alteração do critério de contagem de tempo para aposentadoria baseada no tempo de contribuição em substituição ao tempo de serviço. Contudo, a expectativa em torno dessa alteração é que seus efeitos sejam bastante reduzidos. A introdução dessa mudança foi motivada pelo princípio segundo o qual apenas os trabalhadores que tenham efetivamente contribuído para o sistema previdenciário tenham direito aos benefícios. Porém, da forma como foi aprovada a alteração, essa medida terá poucos efeitos práticos, pois os trabalhadores que conseguirem comprovar o período mínimo de anos trabalhados através da "carteira assinada", por exemplo, não serão obrigados a comprovar o efetivo recolhimento das contribuições, uma vez que tal recolhimento é realizado pelo empregador.

No caso da ampliação no período de contribuição e da introdução das regras de transição, os efeitos deverão ser positivos, porém diferidos ao longo do tempo, sendo insuficientes para alterar os desequilíbrios do sistema no curto prazo. 
O fim da aposentadoria proporcional, segundo alguns estudos (ver Oliveira et al., 1999), deverá apenas postergar a ampliação do volume de despesas às quais o sistema previdenciário estará sujeito nos próximos anos. $\mathrm{O}$ trabalho mencionado aponta ainda que o fim da opção pelos benefícios proporcionais poderá potencializar o montante de despesas que o sistema deverá suportar, pois implica, necessariamente, que a totalidade dos benefícios pagos corresponda a $100 \%$ do valor máximo a que tem direito cada um dos beneficiários. Em oposição a isso, a opção pela aposentadoria proporcional contemplada no antigo regime da previdência permitia que parte dos benefícios pagos fossem inferiores a 100\% do valor máximo a que os beneficiários teriam direito, funcionando como mecanismo potencial de redução do total das despesas do sistema.

Por fim, a questão mais polêmica diz respeito à exigência combinada de tempo de contribuição e idade mínima. Inicialmente, o texto da reforma pretendia que essa exigência se estendesse não só aos funcionários públicos, mas também aos segurados do INSS. Contudo, no caso dos últimos, tal exigência foi derrubada pelo Congresso Nacional, frustrando parte das expectativas do governo de reduzir o número de aposentadorias precoces na esfera da iniciativa privada e com isso dar um passo em direção ao reequilíbrio das contas do INSS.

Diante disso, parece estar claro que os significativos esforços postos em prática para a aprovação das mudanças no regime previdenciário brasileiro se deram em torno de uma reforma bastante tímida e que pouco deverá contribuir para a efetiva solução dos graves desequilíbrios estruturais do sistema, mesmo a médio e longo prazos. Adicionalmente, mesmo que as transformações no sistema fossem mais profundas do que as que ocorreram, devido à natureza do problema envolvido - elevado estoque de passivos decorrente de direitos adquiridos - tais alterações teriam efeitos imediatos bastante diminutos, contribuindo precariamente com a redução do déficit fiscal gerado pelo sistema no curto prazo. Assim, a garantia imediata de efeitos mais significativos exigiria, necessariamente, ampliações substanciais nas alíquotas de contribuição dos atuais contribuintes e/ou beneficiários em ambos os sistemas (trabalhadores do serviço público e da iniciativa privada), algo não contemplado pela reforma e de difícil assimilação tanto pela sociedade quanto pelo poder Legislativo, a quem cabe aprovar tais alterações. Vale ressaltar que as tentativas de ampliação dos percentuais de contribuição para seguridade social dos funcionários públicos no bojo do ajuste fiscal acordado com o FMI, conforme veremos mais adiante, esbarraram em entraves jurídicos que comprometeram a aprovação da medida. 
Quadro 1: Reforma da Previdência - Regras Anteriores à Reforma e Novas Regras

\begin{tabular}{|c|c|c|}
\hline Regras Anteriores & $\begin{array}{l}\text { Regras atuais } \\
\text { Funcionário Públicos }\end{array}$ & $\begin{array}{l}\text { Regras Atuais } \\
\text { Segurados do INSS }\end{array}$ \\
\hline \multicolumn{3}{|c|}{ I. Aposentadoria Integral } \\
\hline $\begin{array}{l}35 \text { anos de serviço } \\
\text { - Homens (H) } \\
30 \text { anos de serviço } \\
\text { - Mulheres (M) }\end{array}$ & $\begin{array}{l}\text { los de idade e } 35 \text { anos de } \\
\text { ibuição }(\mathrm{H}) \\
\text { los de idade e } 30 \text { anos de } \\
\text { ibuição (M) } \\
\text { rão comprovar } 10 \text { anos } \\
\text { rviço público e } 5 \text { anos no } \\
\text { em que se aposentará. }\end{array}$ & $\begin{array}{l}35 \text { anos de contribuição }(\mathrm{H}) \\
30 \text { anos de contribuição (M) } \\
\text { Sem limite de idade }\end{array}$ \\
\hline \multicolumn{3}{|c|}{ II. Aposentadoria Proporcional } \\
\hline $\begin{array}{l}30 \text { anos de serviço }(\mathrm{H}) \\
25 \text { anos de serviços }(\mathrm{M})\end{array}$ & Extinta & Extinta \\
\hline \multicolumn{3}{|c|}{ III. Professores } \\
\hline $\begin{array}{l}30 \text { anos de magistério }(\mathrm{H}) \\
25 \text { anos de magistério }(\mathrm{M}) \\
\text { Proventos integrais nos dois } \\
\text { casos }\end{array}$ & $\begin{array}{l}\text { Ensino básico e médio: } \\
\text { requisitos de idade e } \\
\text { tempo de contribuição } \\
\text { reduzidos em } 5 \text { anos. } \\
\text { Ensino universitário: mes- } \\
\text { mas regras dos demais } \\
\text { servidores }\end{array}$ & $\begin{array}{l}\text { Ensino básico e médio: tempo de } \\
\text { contribuição reduzidos em } 5 \text { anos. } \\
\text { Ensino universitário: mesmas re- } \\
\text { gras dos demais servidores }\end{array}$ \\
\hline \multicolumn{3}{|c|}{ IV. Aposentadoria por idade } \\
\hline $\begin{array}{l}65 \text { anos de idade }(\mathrm{H}) \\
60 \text { anos de idade }(\mathrm{M}) \\
\text { Proventos proporcionais ao } \\
\text { tempo de serviço }\end{array}$ & $\begin{array}{l}65 \text { anos de idade }(\mathrm{H}) \\
60 \text { anos de idade }(\mathrm{M}) \\
\text { Proventos proporcionais a } \\
\text { tempo de serviço }\end{array}$ & $\begin{array}{l}65 \text { anos de idade }(\mathrm{H}) \\
60 \text { anos de idade }(\mathrm{M}) \\
\text { Mínimo de } 9 \text { anos de contribuição e } \\
\text { proventos proporcionais ao tempo } \\
\text { de contribuição }\end{array}$ \\
\hline \multicolumn{3}{|c|}{ V Aposentadoria Compulsória } \\
\hline $\begin{array}{l}70 \text { anos de idade (servidores } \\
\text { públicos) } \\
70 \text { anos }(\mathrm{H}) \text { e } 65 \text { anos (M) } \\
\text { para os segurados do INSS } \\
\text { Proventos proporcionais ao } \\
\text { tempo de serviço }\end{array}$ & $\begin{array}{l}70 \text { anos de idade (servi- } \\
\text { dores públicos) Proventos } \\
\text { proporcionais ao tempo } \\
\text { de serviço. }\end{array}$ & $\begin{array}{l}70 \text { anos de idade }(\mathrm{H}) \\
65 \text { anos de idade }(\mathrm{M}) \\
\text { Proventos proporcionais ao tempo } \\
\text { de serviço. }\end{array}$ \\
\hline
\end{tabular}

Fonte das informações originais: Ministério da Previdência (1999). 
Quadro 2

Reforma da Previdência - Regras de Transição

\begin{tabular}{ll}
\hline Funcionários Públicos & \multicolumn{1}{c}{ Segurados do INSS } \\
\hline 53 anos de idade e 30 anos de contribuição & $\begin{array}{l}\text { I. Aposentadoria Integral } \\
\text { contribuição (M) Sem limite de idade e sem } \\
\text { - homens (H) }\end{array}$ \\
48 anos de idade e 25 anos de contribuição & \\
- mulheres (M) & \\
Deverão acrescentar tempo de contribuição \\
para aposentadoria pela regra anterior à reforma. \\
Comprovar 5 anos no cargo em que se aposentará. \\
Fica extinta a contagem de tempo fictício para \\
efeito de aposentadoria
\end{tabular}

\section{Aposentadoria Proporcional}

Mesmos requisitos de tempo de contribuição e idade mínima para aposentadoria integral. Acréscimo de $40 \%$ ao tempo que faltava para aposentadoria pela regra anterior à reforma
53 anos de idade e 30 anos de contribuição homens $(\mathrm{H})$

48 anos de idade e 25 anos de contribuição mulheres (M)

Acréscimo de $40 \%$ ao tempo que faltava para aposentadoria pela regra anterior à reforma.

\section{Professores}

Receberão um acréscimo de 17\% (H) e 20\% (M) Receberão um acréscimo de 17\% $(\mathrm{H})$ na contagem do tempo de magistério até 16/12/98. e 20\% (M) na contagem do tempo de A partir desse acréscimo, seguirão as mesmas regras dos demais servidores. magistério até 16.12.98. A partir desse acréscimo, seguirão as mesmas regras dos demais segurados do INSS.

\begin{tabular}{ll}
\hline \multicolumn{2}{c}{ IV. Juízes. Membros do Magistério Público e Tribunais de Contas } \\
\hline $\begin{array}{l}\text { Regras semelhantes às validas para os } \\
\text { professores. }\end{array}$ & Não se aplica \\
\hline \multicolumn{1}{c}{ V. Aposentadoria por Idade } \\
\hline 65 anos de idade (H) 60 anos de idade (M) & 65 anos de idade (H) \\
Proventos proporcionais ao tempo de serviço & 60 anos de idade (M) \\
& Mínimo de 9 anos de contribuição e \\
& proventos proporcionais ao tempo de \\
& contribuição. \\
\hline & VI. Aposentadoria Compulsória \\
\hline & 70 anos de idade (H) \\
70 anos de idade (servidores públicos) Proventos & 65 anos de idade (M) \\
proporcionais ao tempo de serviço & Proventos proporcionais ao tempo de \\
& serviço. \\
\hline
\end{tabular}

Fonte das informações originais: Ministério da Previdência (1999). 
Adicionalmente às deteriorações das contas primárias verificadas entre 1994 e1998, conforme vimos anteriormente, as despesas financeiras do setor público sofreram forte elevação no mesmo período. A análise dos dados referentes às NFSP contidos na Tabela 3 demonstra claramente que os desajustes financeiros das contas públicas no período de vigência do Plano Real sobrepuseram-se acentuadamente aos desequilíbrios no resultado primário.

Tabela 3

Necessidades de Financiamento do Setor Público - 1995/1998

(em\% do PIB)

\begin{tabular}{lcccc}
\hline Governo Consolidado & 1995 & 1996 & 1997 & 1998 \\
\hline Primárias & $-0,35$ & 0,09 & 1,02 & $-0,01$ \\
Juros Reais & 5,23 & 3,66 & 3,31 & 7,73 \\
Operacionais & 4,88 & 3,75 & 4,33 & 7,72 \\
Nominais & 7,18 & 5,87 & 6,14 & 8,03 \\
\hline Governo Central & & & & \\
Primárias & $-0,58$ & $-0,37$ & 0,33 & $-0,57$ \\
Juros Reais & 2,24 & 2,00 & 1,44 & 5,97 \\
Operacionais & 1,67 & 1,62 & 1,77 & 5,40 \\
Nominais & 2,31 & 2,56 & 2,64 & 5,47 \\
\hline Estados e Municípios & & & & 0,20 \\
Primárias & 0,17 & 0,54 & 0,74 & 1,61 \\
Juros Reais & 2,18 & 1,27 & 1,53 & 1,82 \\
Operacionais & 2,35 & 1,81 & 2,27 & 2,04 \\
Nominais & 3,56 & 2,71 & 3,04 & 0,35 \\
\hline Empresas Estatais & & & & 0,15 \\
Primárias & 0,05 & $-0,08$ & $-0,06$ & 0,50 \\
Juros Reais & 0,81 & 0,39 & 0,35 & 0,51 \\
Operacionais & 0,86 & 0,32 & 0,29 & 0,45 \\
Nominais & 1,31 & 0,61 & 2,04 & \\
\hline
\end{tabular}

Percentual positivo = déficit, e percentual negativo = superávit. Governo Central inclui Tesouro Nacional e Banco Central. Exclui receitas de privatizações.

Fonte: Boletim do Banco Central do Brasil, diversos números.

Pode-se afirmar que desde a introdução do plano Real até o momento da alteração no regime cambial, em janeiro de 1999, a adequação da política monetária ao objetivo de manutenção da âncora cambial resultou em dois focos de desequilíbrio macroeconômico, quais sejam: (i) a ocorrência de expressivos déficits comerciais e em transações correntes; e (ii) o significativo ônus imposto às contas financeiras do setor público. O mix de políticas cambial e monetária que sustentou os primeiros quatro anos do plano levou não só à progressiva fragilização externa do país, ampliando a dependência em relação ao financiamento estrangeiro (de curto 
e de longo prazo), como também ao crescimento extraordinário do déficit operacional do governo consolidado e à constituição de uma trajetória explosiva para o endividamento público. A dívida líquida total do setor público, que era de R \$210 bilhões em dezembro de 1994 (a preços de dezembro de 1998), ou 28,5\% do PIB, chegou a R\$ 389 bilhões em dezembro de 1998, ou 42,6\% do PIB. A dívida mobiliária do governo federal passou de R \$ 83 bilhões, ou 11,2\% do PIB, para R \$ 323 bilhões, ou $35,4 \%$ do PIB, no mesmo período assinalado anteriormente.

A associação desse cenário, que progressivamente explicitava as inconsistências da política macroeconômica interna, e a emergência da crise financeira internacional iniciada com a quebra dos países asiáticos, em finais de 1997, e que culminou com a moratória da dívida externa da Rússia em meados de 1998, impuseram ao país a realização de um acordo de socorro financeiro internacional coordenado pelo $\mathrm{FMI}^{8}$ em outubro de 1998 e, posteriormente, a alteração do regime cambial em janeiro de 1999.

Considerando-se apenas os efeitos da mudança na política cambial sobre as variáveis fiscais, a importância dessa alteração reside na possibilidade de solução de grande parte das questões que determinaram o desequilíbrio financeiro do setor público no período de vigência do atual programa de estabilização, qual seja, a manutenção das taxas de juros internas num patamar elevado. A possibilidade de flutuação do câmbio reduz a importância da taxa de juros doméstica enquanto instrumento na busca do equilíbrio externo da economia, possibilitando uma sensível redução das taxas de juros reais e, consequentemente, das despesas financeiras do setor público, contribuindo para o objetivo de reduzir as NFSP operacionais e alcançar uma trajetória de endividamento público sustentável no longo prazo.

Contudo, no curtíssimo prazo, a desvalorização do real implicou num forte impacto sobre as NFSP e o estoque da dívida líquida do setor público. Também como parte da estratégia de manutenção da âncora cambial a participação dos títulos públicos indexados ao dólar ampliou-se significativamente desde a introdução do Plano Real, passando de 8,3\% da dívida mobiliária, em 1994, para 21 \% em janeiro de 1998. Com a desvalorização de janeiro de 1999, essa participação ampliou se para 30,4\% (no mesmo mês), elevando-se também a relação dívida líquida total/PIB, de 42,6\% em dezembro 1998 para 51,8\% em janeiro de 1999.

Diante da mudança cambial, as metas fiscais estabelecidas quando do anúncio da primeira rodada de negociação com FMI em outubro de 1998 - superávits primários de 2,6\% (ou R \$ 28 bilhões), 2,80\% e 3,0\% do PIB para o período 1999/ 2001 com estabilização da relação dívida/PIB em torno de 44,4\% em 2001 - tiveram que ser revistas a fim de incorporar os impactos da desvalorização sobre as contas públicas (ver IMF 1999a e 1999b).

As medidas fiscais decorrentes do acordo têm como principal objetivo recuperar a credibilidade do país no mercado internacional, através da absorção dos

\footnotetext{
${ }^{8} \mathrm{O}$ acordo assinado entre o Brasil e o FMI e os países do G-7 envolveu um programa de ajuda financeira para o país no montante de US\$ 40 bilhões.
} 
impactos da desvalorização sobre relação dívida líquida do setor público/PIB e sua estabilização, através da geração de sucessivos superávits primários nos três anos seguintes (3,1\% do PIB em 1999 [ou R \$ 30 bilhões], 3,25\% do PIB em 2000 e $3,35 \%$ do PIB em 2001). Segundo o acordo, o esforço fiscal será concentrado no Governo Central, que deverá gerar superávits primários como proporção do PIB de $2,4 \%$ em $1999,2,65 \%$ em 2000 e 2,6\% em 2001. Aos estados e municípios caberá um esforço de $0,5 \%$ do PIB, em média, ao longo dos três anos, e às empresas estatais, de $0,2 \%$ do PIB, também em média no mesmo período.

Para que esses resultados sejam atingidos o governo procurou valer-se do conjunto de medidas detalhadas a seguir (ver Ministério da Fazenda, 1998):

a. redução do déficit da previdência dos servidores públicos federais através da extensão da contribuição previdenciária de $11 \%$ aos servidores inativos civis e da adoção de uma alíquota adicional temporária de $9 \%$, incidente sobre a parcela que exceder $\mathrm{R} \$ 1.200,00$ do salário de todos os funcionários públicos civis (ativos e inativos); esta medida foi amplamente contestada judicialmente, fato que inviabilizou sua aplicação;

b. prorrogação da CPMF - que deveria ser extinta em fevereiro de 1999 - até 2001. Essa prorrogação será acompanhada de elevação da alíquota de $0,2 \%$ para $0,38 \%$ em 1999 e $0,3 \%$ a partir de 2000 . A receita proveniente dessa elevação será desvinculada dos gastos com saúde;

c. extensão da cobrança da COFINS às instituições financeiras e elevação de alíquota da mesma em um ponto percentual, permitindo a compensação com o IRPJ;

d. alteração na legislação que trata da Contribuição Social sobre Lucro Líquido, implicando em maior pagamento por parte das instituições financeiras;

e. ampliação da base de incidência do IOF e elevação temporária de sua alíquota de $0,20 \%$ para $0,38 \%$, durante o período de carência entre a aprovação da nova CPMF e sua entrada em vigor;

f. incorporação de um conjunto de receitas extraordinárias à arrecadação corrente, como é o caso daquelas oriundas do processo de privatização de algumas empresas públicas (telecomunicações, distribuidoras de energia elétricas) que serão contabilizadas como receitas de concessão;

g. incorporação de depósitos judiciais à receita tributária corrente;

h. cortes da ordem de $20 \%$ na rubrica Outras despesas de Custeio e Capital em 1999;

i. cortes da ordem de R \$ 2,7 bilhões (0,29\% do PIB), por ano, no orçamento das empresas estatais federais no período 1999/2001;

j. adoção de medidas administrativas que visam reduzir o déficit do INSS através de redução das renúncias fiscais e combate à sonegação de contribuições; e 
k. encaminhamento da regulamentação das reformas estruturais já aprovadas no Congresso (Reformas Administrativa e da Previdência), assim como a proposição da Lei de Responsabilidade fiscal, que definirá mecanismos para assegurar o cumprimento das metas fiscais e os critérios para responsabilização dos administradores públicos que desrespeitarem a Lei.

A análise do conteúdo das medidas expostas acima deixa claro que o ajuste fiscal subjacente ao acordo com o FMI compõe-se predominantemente de medidas de curto prazo que atacam apenas de maneira superficial os focos de desequilíbrio das contas públicas primárias já discutidos ao longo deste texto. Mantendo a mesma tônica da política fiscal nos últimos cinco anos, o programa recente está fundamentado na ampliação ad hoc de receitas para o governo federal acompanhada de medidas localizadas de restrição dos investimentos e gastos de custeio da máquina estatal. A ênfase voltada para o ajustamento via ampliação temporária da arrecadação pode ser percebida pela análise dos números relativos ao esforço fiscal projetado para 1999, estimado em R $\$ 30$ bilhões, uma vez que algo em torno de $64 \%$ desse total deverá ser obtido através de aumentos de receitas.

Adicionalmente, a contestação judicial de uma medida importante como a ampliação da cobrança da contribuição para a seguridade social dos funcionários públicos (ativos e inativos) poderá ameaçar inclusive os efeitos de curto prazo do ajuste fiscal, frustrando as expectativas de absorção dos impactos da desvalorização cambial sobre a trajetória de endividamento do setor público.

Portanto, pode-se afirmar que o programa de ajuste fiscal proposto para o período 1999/2001 segue as mesmas bases da política fiscal adotada desde a introdução do Plano Real, ou seja, uma política baseada na tentativa de administrar os desequilíbrios fiscais com uma abordagem de curto prazo, sem avanços significativos na solução das causas estruturais do déficit público. Uma vez que, conforme vimos na seção anterior, parcela importante das reformas estruturais propostas pelo governo desde a introdução do Plano Real ainda permanece aguardando votação no Legislativo, e aquelas já aprovadas deverão contribuir de maneira muito mais tímida para o reequilíbrio das contas públicas do que inicialmente se esperava, pode se afirmar que a solução dos desajustes do setor público em base de mais longo prazo ainda permanece em aberto.

Assim, mesmo aceitando-se a hipótese de que o acordo com o FMI seja cumprido integralmente e que o governo atinja seu objetivo de curto prazo de conter a trajetória de crescimento acelerado da dívida pública, as próprias características do acordo, conforme explicitado acima, não irão garantir a eliminação dos desajustes estruturais do setor fiscal e, portanto, um possível retorno de pressões sobre a trajetória de endividamento público. Desse modo, pode-se argumentar que eventuais avanços obtidos com a implementação do ajuste fiscal proposto para os anos de 1999 a 2001 não significarão uma alteração substancial na condução da política fiscal já posta em prática desde o início do Plano Real. 


\section{CONCLUSÃO}

Este trabalho pretendeu demonstrar que o sucesso da estratégia de combate à inflação iniciada em 1994, ao eliminar um importante mecanismo de realocação real de recursos fiscais, colocou em relevo as fragilidades da estrutura de gastos e receitas do setor público como um todo.

Pode-se afirmar que o caráter estrutural do desajuste fiscal brasileiro já havia sido percebido desde o início da década atual, tendo ganho grande destaque com a introdução do Plano Real. Ainda assim, a política fiscal posta em prática a partir de 1994 tem priorizado a gestão de curto prazo das contas públicas, como forma de buscar a estabilidade macroeconômica enquanto se aguarda a efetivação das reformas estruturais.

Nota-se que a condução da política fiscal nos anos recentes tem sido marcada pela ênfase na busca de ampliação das receitas a fim de enfrentar a crescente necessidade de recursos gerada pela ampliação dos gastos primários, contudo sempre através de medidas cujos efeitos são restritos ao curto prazo. Nesse sentido, pode se argumentar que o persistente desajuste fiscal verificado nos últimos anos não pode ser creditado a restrições observadas no lado da arrecadação, mas sim à manutenção de um conjunto de gastos rígidos, cuja eliminação tem sido dificultada devido à exigência de alterações estruturais no setor público através de mudanças constitucionais.

Adicionalmente, os gastos fiscais foram fortemente impactados pelo mix de políticas macroeconômicas que deu sustentação à estratégia de estabilização implementada em 1994. A necessidade de manter taxas de juros relativamente elevadas, sobretudo em momentos de crise internacional, restringiu ainda mais as possibilidades de redução das despesas, ampliando a componente financeira do déficit fiscal. Esse conjunto de elementos permite dizer que mesmo que os expressivos superávites primários previstos no acordo com o FMI firmado em 1998 venham a ocorrer; tal fato não representará senão uma melhora conjuntural das contas fiscais. Isto porque a obtenção de um ajuste fiscal sustentado permanece na dependência de um amplo conjunto de reformas que, ou continuam em discussão, ou só apresentarão resultados a longo prazo.

\section{REFERÊNCIAS}

ALÉM, A.C. e GIAMBIAGI, F. 1999. “O Ajuste do Governo Central: além das reformas” ln: GIAMBIAGI, F. e MOREIRA, M.M. Economia Brasileira nos Anos 90. Rio de Janeiro: BNDES.

BANCO CENTRAL DO BRASIL. 1996. Boletim do Banco Central do Brasil. Separata: Evolução da

Economia Brasileira após o Plano Real. Brasília: Banco Central do Brasil/Diretoria de Política Econômica/ Departamento Econômico, julho. . Boletim Mensal, vários números.

IMF 1999a Brazil - Memorandum of Economic Policies. www.imf.org. .1999b Brazil - Technical Memorandum of Understanding. www.imf.org. 
MINISTÉRIO DA ADMINISTRAÇÃO E REFORMA DO ESTADO. 1999. Regulamentação da Reforma Administrativa. www.mare.gov.br (Home Page na Internet).

MINISTÉRIO DA FAZENDA. 1998. Programa de Estabilização Fiscal. www.fazenda.gov.br (Home Page na Internet).

MINISTÉRIO DA PREVIDÊNCIA. 1999. Como Você Fica com a Refoma da Previdência. www.mpas. gov.br (Home Page na Internet).

OLIVEIRA, F.E.B. et al., 1999. "Alternativas de Reforma Estrutural da Previdência”. Rio de Janeiro: IPEA - Nota Técnica (mimeo).

RAMOS, A. P. 1998. Estabilização e Política Económica: A Experiência do Plano Real. Campinas: II/ Unicamp, Dissertação de Mestrado (mimeo).

VELlOSO, R. 1998. “A Situação das Contas Públicas após o Real”. Ln VELLOSO, J. P. R. O Brasil e o Mundo no Limiar do Novo Século. Vol II. X Fórum Nacional. Rio de Janeiro: José Olympio. 